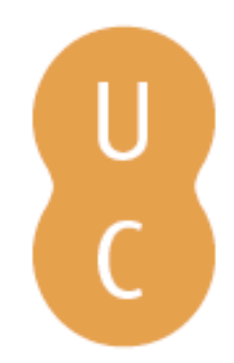

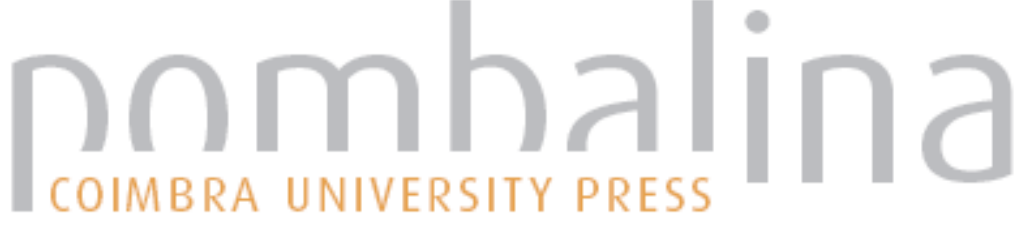

\section{Na luz de Platão: de Petarca a Camões}

Autor(es): Lourenço, Eduardo

Publicado por: Imprensa da Universidade de Coimbra

URL

persistente: URI:http://hdl.handle.net/10316.2/31276

DOI: $\quad$ DOI:http://dx.doi.org/10.14195/978-989-26-0569-2_50

Accessed : $\quad$ 26-Apr-2023 14:57:53

A navegação consulta e descarregamento dos títulos inseridos nas Bibliotecas Digitais UC Digitalis, UC Pombalina e UC Impactum, pressupõem a aceitação plena e sem reservas dos Termos e Condições de Uso destas Bibliotecas Digitais, disponíveis em https://digitalis.uc.pt/pt-pt/termos.

Conforme exposto nos referidos Termos e Condições de Uso, o descarregamento de títulos de acesso restrito requer uma licença válida de autorização devendo o utilizador aceder ao(s) documento(s) a partir de um endereço de IP da instituição detentora da supramencionada licença.

Ao utilizador é apenas permitido o descarregamento para uso pessoal, pelo que o emprego do(s) título(s) descarregado(s) para outro fim, designadamente comercial, carece de autorização do respetivo autor ou editor da obra.

Na medida em que todas as obras da UC Digitalis se encontram protegidas pelo Código do Direito de Autor e Direitos Conexos e demais legislação aplicável, toda a cópia, parcial ou total, deste documento, nos casos em que é legalmente admitida, deverá conter ou fazer-se acompanhar por este aviso. 


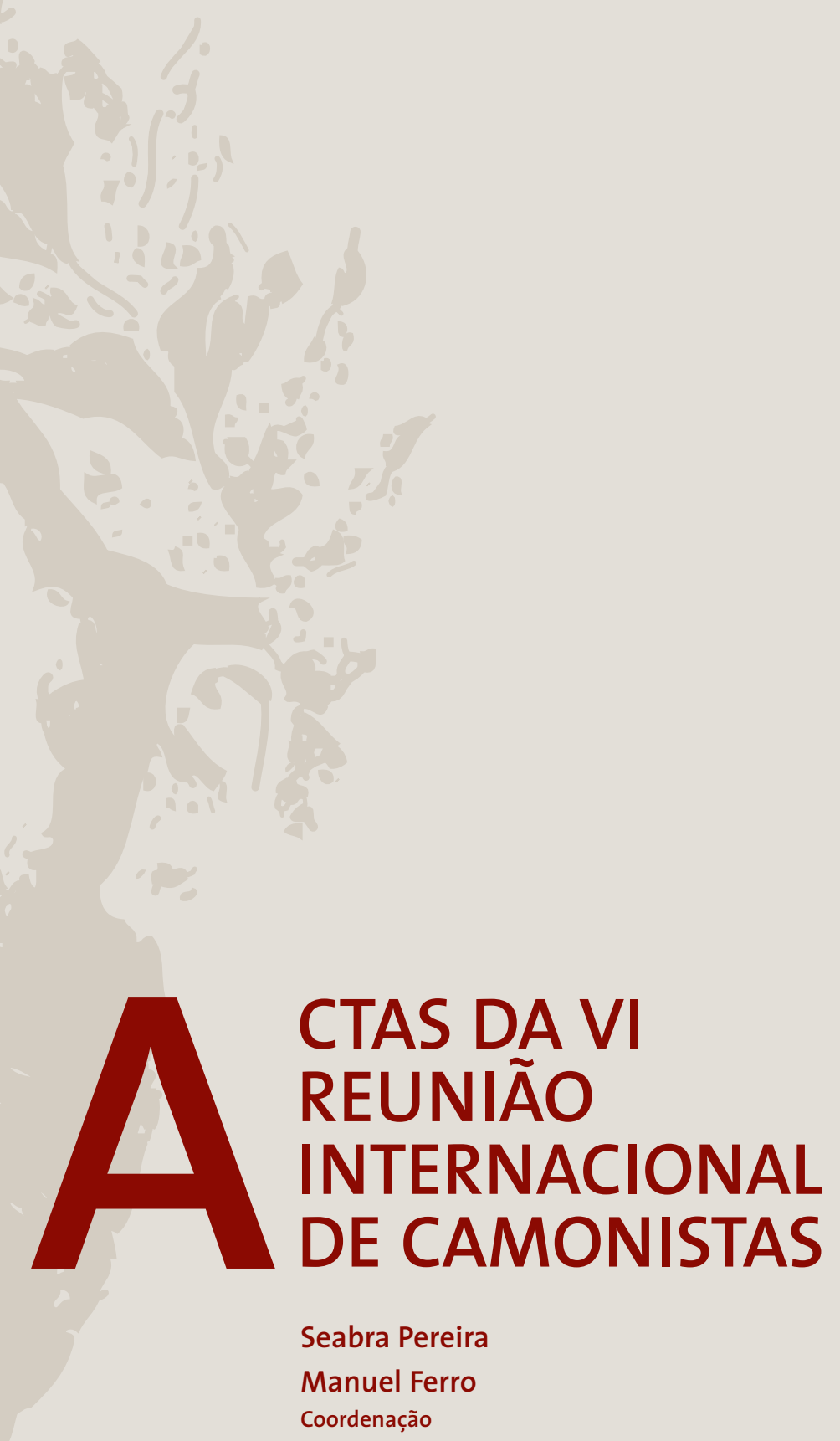


Eduardo Lourenço

Universidade de Nice

NA LUZ DE PLATÃO: DE PETRARCA A CAMÓES

Mais de dois séculos separam Petrarca de Camóes, quase dois de Garciláso. É de crer que, na ordem complexa da criação espiritual e poética, o impacto do tempo e das transformaçôes que ele pode comportar em épocas da autêntica revolução civilizacional e cultural, como foram as que sinteticamente confluíram no Renascimento, não é da mesma natureza. A História, a sensibilidade, o que chamamos visão do mundo, do tempo de Petrarca e dos dois maiores poetas petrarquisantes da Península, parecem quase inconciliáveis, ou apenas aproximáveis para sublinhar o que os distingue e náo o que por cima da temporalidade exterior os possa mover. Mas no mundo do espírito, como se dizia ao tempo de Valéry, ou da Cultura como ainda se diz hoje, a temporalidade obedece a outra lógica. Pode aproximar-se mais daquela que se visa na ordem religiosa quando se fala na comunháo dos santos.

No caso das relaçôes entre Petrarca e os que deviam ser vistos como os seus longínquos filhos poéticos, essa lógica mística foi singularmente ajudada pelo primeiro grande milagre comunicacional, o de Gütemberg. Em manuscrito, Petrarca, como Dante, como Boccacio, poderiam ter ficado num tempo quase inacessível. O Canzionere, impresso nos alvores do Renascimento, tornou-se de súbito e de novo contemporâneo dos poetas e dos homens cultos do século XVI. É por demais conhecida a maneira como através da célebre publicação dos poemas de Boscán e também de Garciláso, se não o próprio Petrarca, a sua lírica se converteu num modelo e revolucionou a constelação poética da Península. Em que sentido e com que consequências é o que importa ao nosso propósito e em particular à presença do platonismo que à sua influência se deveria.

Como já não estamos na época em que as ideias acerca do platonismo e sobretudo do não platonismo circulavam como imagens de Épinal, segundo a expressão feliz de Vítor Aguiar e Silva no seu primeiro livro de ensaios camonianos (Camóes: Labirintos e Fascinios), contribuição magna para o nosso tema, talvez seja ocioso relembrar uma famosa e injustíssima boutade do meu muito amado Pessoa. Todos se lembram que Pessoa, para marcar a sua pouca consideração pela lírica camoniana, insinuou claramente, - ou publicou - que todas aquelas comoventes lágrimas camonianas corriam directamente dos olhos de Petrarca. Quer dizer, estávamo-nos comovendo com ele em lugar do outro. Isto é, naturalmente, indefensável, mas tem ao menos o mérito de sublinhar em estilo provocante que Camóes não é verdadeiramente inteligível - e paradoxalmente apreensível na sua autêntica originalidade - fora da constelação lírica que tem Petrarca 
no centro. E o mesmo se diga, até com mais razão, de Garciláso. Sabe-se isso, diz-se isso, mas passa-se à frente, ou bastante ao lado, para não suscitar não sei que eruditos ciúmes em Amor e Marte.

A presença petrarquista e o género dela já foi objecto de considerável atenção em Espanha. Mas, se não cometo imprudência, não suficientemente em Portugal até ao recentíssimo exame de Aguiar e Silva. Claro que já foram assinaladas, e há muito tempo, pelo mais célebre dos seus comentadores os emprunts que tanto Garciláso como Camóes fizeram ao texto petrarquiano. Mas muito como quem assinala que este ou aquele pedacinho de pedra provêm da pirâmide de Gizeh. Não é bem, nem de modo algum o caso. Os mundos de Garciláso e de Camóes - mesmo com outro género de mediaçôes como os de Ariosto ou Sannazaro - não em termos de imitacio do perfil positivista, mas objectivamente, convivem e conviverão para sempre com o de Petrarca, não por repetição de sintagmas numerosos ou estilemas, nem sequer por afinidade de temática amorosa ou de adopção dos mesmos, ou parecidos, esquemas formais - e não é pouco - mas porque são etapas de mitologia amorosa a que Petrarca deu uma configuração ao mesmo tempo imitável e inimitável e através dela, de uma re-escrita com o novo espírito - sobretudo no que diz respeito a Camóes - dos textos fundadores da melancolia Moderna que são o Cancionere e o Trionfi.

Homem do Renascimento, um - com o que isso sugere, ou sugeria ainda no tempo de solar primavera do mundo, com o Homem no seu centro -, Homem do seu crepúsculo o de um novo tempo, o outro, ambos estão inscritos nessa galáxia de Melancolia que é feita apenas de consciência intensa - e no caso de Camóes dolorosa e desesperada - de terem entrado num mundo náo apenas dominado pela Fortuna - deusa do Acaso, do desconcerto ou do sentido em plena cultura cristá, outrora guiada e sustentada na ideia da Providência mas pela convicção, bem mais forte que a do próprio Petrarca, da ausência de finalidade redentora para o obscuro da nossa vida. Une-os a todos, naturalmente, a paixão ou o culto da Beleza, da beleza terrestre em si e do seu papel enquanto educadora e a seu modo consoladora, ou mesmo sob o disfarce, também petrarquiano, da «minha cara inimiga», do impetuoso e cavalheiresco génio em Garciláso ou do mudo génio de vingança camoniana que a amena vida do cantor de Laura necessitou menos. Mas no texto dos seus poemas - que é o único espelho fiável dos seus destinos para nós - desune-os a diversa forma, e não só, com que a vida os viveu mas como eles viveram a crucial experiência do amor, malgrado a forma, o tipo de cultura, a memória mítica em que a converteram e no-la deram a ver.

Claro que não é possível esquecer a famosa atmosfera espiritual e intelectual das respectivas épocas, com a avassaladora impregnação neo-platónica que aproxima Garciláso de Camóes e separa ambos de Petrarca. E desta impregnação, em fiel sintonia com a metafísica do Amor de Marcilio Ficino, sem precisarmos de recorrer aos Bembo e aos Leão Hebreu que lhe deram uma forma mais acessível, faz parte de uma maneira diversa da figura e do sentido que o Amor tem em Petrarca, uma outra ideia dele, que é a de uma energia universal que percorre o Universo e que não podemos identificar ao Amor que na Divina Comédia (e na divisão cristã do mundo mais tradicional) move o sol e as estrelas, nem ao Amor segundo Petrarca que é a sublimação de um amor incomparável e único ou - como antídoto - a Graça que, através da morte, o redime e o eleva a uma condição eterna. 
Há já ninfas, decorativamente amáveis símbolos da Beleza que em Laura está mais perfeita, mas náo Faunos como em Camóes superlativamente existem, expressão desse amor que se confunde com a vida mesma e sua indomável omnipotência sobre a Natureza, os homens, os heróis, os próprios deuses. Ou em Garciláso com menos fervor erótico, como na Elegia Primeira - género compósito como já aqui foi sublinhado - composição grave dirigida ao Duque de Alba para o consolar pela morte do jovem irmáo e em que o Poeta, para remédio de tanta tristeza, lhe aconselha, mais epicuristicamente, que se distraia com ninfas e sátiros. É nessa passagem de Garciláso que, como tantas, vem relembrar alguma coisa aos leitores dos Lusíadas:
"Sátiros, faunos, ninfas, cuya vida sem enojo es para, moradores de la parte repuesta y escondida, com luenga experiência sabidores, buscad para consuelo de Fernando hierbas de propriedad oculta y flores; así en el escondido bosque, cuando ardiendo en vivo y aguada de fuego las fugitivas ninfas vais buscando, ellas se inclinan al piedoso ruego y en recipro lazo están ligadas, sin arquivar el amoroso juego.”

Este quadro que só o Renascimento no seu esplendor pagáo podia inspirar, com o mais famoso guerreiro em Leonardo camoniano, além do lado picante e insólito de estar inserido numa consolação, dá às consabidas, mas então ainda inexpressas relaçóes abissais entre Eros e Thanatos, o lugar que ele tem na vida, mas a que tão sensível foi a poesia da gente para quem o jogo do amor e os jogos da morte eram, por assim dizer, a maior ocupação. Esta relação é em Camôes igualmente imensa pois, como Garciláso, era homem de pena e espada, a expressão é de Garciláso... Não é nestes tempos que Eros e a Morte dialogam na lírica petrarquiana. Adoçam-se um com a outra num processo de transfiguração do sujeito amoroso ou da morte, pela mesma morte sublimada, como num dos mais belos versos jamais escritos: La Morte bella parea en su bel viso.

A presença da Morte, não como mera metáfora do sofrer ou morrer pelo cruel amor, num jogo preciosista que vinha do Dolce still nuovo, nada tem de original nem em Garciláso nem em Camôes, salvo que um e outro - mas sobretudo Camóes nos Sonetos e nas Cançôes - levam esse jogo a um refinamento que abole todo o trágico inerente às faces de Janus de toda a experiência amorosa. Só com a experiência afectiva da morte da amada - tanto em Garciláso, como em Camôes - o recurso à visão neo-platónica, mais realisticamente em Garciláso, mais idealizante em Camóes, oferece uma resposta ao que a não tem. Garciláso e Camões já habitam com naturalidade - quer dizer em segundo grau - o planeta do amor como literatura, descoberto e percorrido em todos os sentidos por Petrarca. Por isso são mais desenvoltos e menos submissos ao código idolátrico a que o poeta de Laura se submeteu. 
São poetas de várias flamas ou, pela escassa vida, de uma intensa chama, tanto mais que é a de um amor aceite e traído, como em Garciláso. Mas o papel da imortalização, da divinização por Petrarca reservado ao Amor, não será mais esquecido. Na grande poesia do Renascimento os amantes que a morte separa sonharão, também como Petrarca, de uma vida eterna do amor, de uma realização mais duradoura, de um sentimento submetido, "cá na terra", à mudança e à morte. Mas então será a amada que, no quadro neo-platónico de uma orientação do amor, semelhante à dos astros, deterá o poder de chamar para junto dela, no além feliz e eterno onde a morte a instalou, o Poeta que ficou ainda sentado nas margens do tempo. O movimento parece o mesmo de Petrarca e mais o parece num poema com tantas ressonâncias petrarquistas, como o mais que célebre Alma minha gentil que te partiste.

Todos sabemos que Camóes pede à mulher amada que o chame para junto dela. Mas não nos ofusquemos com este dualismo tão clássico e de certo modo tão cristão entre céu e terra e entre amor vivido aqui e lá cima; é sempre da divinização do amor que se trata. E, no caso de Garciláso, essa “outra vida” nada tem de etério, é a mesma vida, o amor terrestre, enfim livro e liberto numa nova terra descrita com a mesma paixão e amor pelas paisagens desta vida que ele visiona para Elisa e onde ele se visiona, no que é uma das mais belas expressóes do sentimento neo-platónico da existência que o Renascimento nos deu:

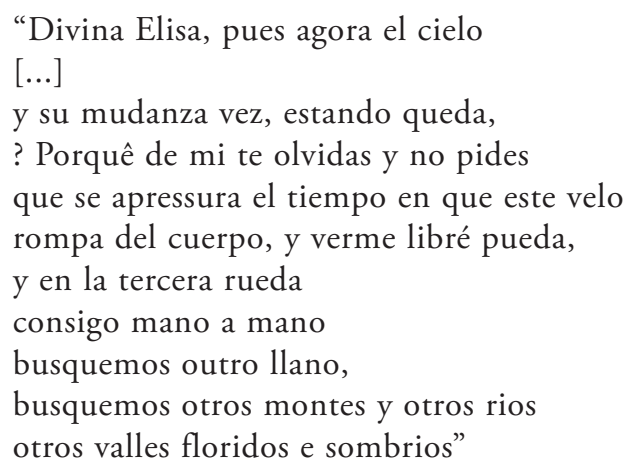

Talvez que se Camóes não tivesse sido tão consciente que era já, inapelavelmente, um habitante de um continente poético-lírico ou épico, não insistisse tanto nas "verdades já por mim pensadas", nas verdades puras. Com efeito, embora tivesse ardido em tantas flamas, Camóes, ao fim e ao cabo, não teve Musa, nem à maneira de Petrarca, mítica e cientemente mitificada, nem à maneira de Garciláso que a teve morta em vida para ela e só viva na morte. Não há tema mais constante em Camões que o da Ninfa em fuga, em perpétua fuga, no fundo pura miragem como Tétis para o Adamastor. O seu destino, humano e de poeta, não era o de subir do céu à terra, mas de tocar terra que abraçada não fosse «nuvem, sombra, fumo ou nada». O neo-platonismo nele - as redondilhas de Sôbolos Rios talvez nos ofusquem em excesso - é um neo-platonismo de sonho, que de resto ele assume para náo sucumbir, tão moderadamente, ou tão pré-barrocamente, ao fascínio da pura ilusão. De tudo, ou do que para ele e para nós será tudo, o consolou a única Musa: o Canto, e seu próprio canto, a Canção, que já na sua primeira invenção era solilóquio da alma a sós consigo. 
Se a essência do platonismo é aspiração infinita, como tal vivida e sentida, como tal pensada, poucas poesias haverá no mundo mais platónicas que a de Camóes. Mas o céu não é nenhum empíreo. É o seu impaciente e insatisfeito coração e, talvez mais ainda, o seu inquieto e inquietante pensamento que não foi apenas acto de meditação ou de desvairados e contrários desejos, mas pensamento do mundo. Do mundo em todos os sentidos mas sobretudo do mundo como enigma exigindo, sem descanso, que o decifremos. Toda a grande poesia é visão do mundo. Mas é num sentido novo e específico que a poesia de Camóes, no seu todo, é verdadeiramente poesia como pensamento do mundo. Pensamento de um mundo novo, num sentido óbvio e exterior, claro está, mas mais profundamente pensamento do lugar do homem neste mundo novo e do homem em geral, que neste mundo novo - de repente - no momento mesmo da sua revelação como universo pleno de maravilhas não mergulha a humanidade - ao menos a que Camóes representava - no êxtase da afirmação e da alegria (salvo em pintura), mas na perturbação da alma e na vertigem do pensar. Pela primeira vez, de uma maneira voluntária, consciente de si mesma, a poesia portuguesa em Camóes torna-se numa forma quase desesperada de atenção ao sentido da vida, ao seu mistério, ao espectáculo de uma contradição que parece afectar, ao mesmo tempo, a ordem do mundo e a ordem do pensamento, para nada dizer do sentimento, campo privilegiado da emoção poética.

Camóes na encruzilhada da cultura europeia, precisamente quando a Idade Média se tornara fantasmagórica e o Renascimento, penetrado do saber deste mundo, se convertia numa Ilha de Amores profanos e de sonhos sem piedade para aqueles que não dispunham nem do poder nem do dinheiro. Somente no seu coração, o primeiro vasto como o mundo, a Poesia se tornou condenação e êxtase, vida como alto Desejo onde o sentido do mundo brilha ainda sem encontrar um objecto à sua medida.

Sem dúvida existe a vida heróica - mas ela pertence ao passado - Os Lusíadas reinventam-na para encontrar nova pátria mais habitável que o presente ensombrecido e há sobretudo o Amor, essência platónica do verdadeiro Desejo, forma de presença e de plenitude que só a ausência salva do desencanto e do tédio, mas que permanece, apesar de tudo, o coração da vida:

"Erros meu, má fortuna, amor ardente,

Para minha perdição se conjuraram.

Os erros e a fortuna sobejaram,

Que para mim bastava amor somente.”

Deste amor in absentia, certas cançôes sob o modo da nostalgia e da saudade de si mesma saudosa são o eco imperecível. Entre toda aquela que é uma espécie da quadratura do círculo do sentimento, maior do que a visão platónica da vida, platonismo do platonismo, a Cançâo $X$ que todos temos na memória, um dos mais belos poemas de amor e da amargura da nossa literatura e creio também da literatura universal:

"Que desculpa comigo que buscava quando o suave Amor mo não sofria culpa na coisa amada, e tâo amada!" 
Que papel tem a idealização platonizante nesta queixa transcendente do mal do amor não o sei dizer. Que é Petrarca sublimado e revolvido em si mesmo, parece-me mais claro. A coisa amada é carinhosamente reduplicada para curar a ferida sem cura do Puro Amor que, se no seu mundo, já não movia tão intensamente o sol e as estrelas como no de Dante, iluminou a noite do seu plural e insolúvel coração. 